\title{
Rheumatoid arthritis: The effect of physical rehabilitation guideline On improvement the Activity of daily living (ADL) of female patients
}

\author{
Howida khalaf Abd-Elaal, Essam Ahmed Mohmed Abda \& Zienab Abd El-lateef Mohamed, \\ B.SC., M.SC.N, Medical - Surgical Nursing-Continuous educational center-Assuit university hospital ,Egypt . \\ Professor of Medical Surgical Nursing Department, Faculty of Nursing Assuit University, Egypt . \\ Professor of Rheumatology and rehabilitation, Faculty of Medicine, Assiut University, Egypt .
}

\begin{abstract}
Rheumatoid arthritis (RA) is the most common inflammatory polyarthritis It can cause persistent joint pain, joint damage and long-term disability (especially in the hands and feet).The goals of management are to prevent or control joint damage, maximize function and decrease pain. Methods: The study was conducted in the Rheumatology department and outpatient clinic at Assiut university hospital, sample including Fifty female patients with RA, divided in two equal groups. Used The Health Assessment Questionnaire (HAQ), The Foot \& Ankle Disability Index (FADI) and Michigan Hand outcome Questionnaire to collected of data. The study showed that there were highly significant statistical improvement $(\mathrm{p}<0.001)$ regarding knowledge, total scores of common daily activity in both groups $(\mathrm{z} \leq 2.58 * *)$, foot and ankle functional status and ADL $(\mathrm{z} \leq 2.58 * *)$ and regarding to over hand function, and hand grip strength .Conclusion: based on the finding of the study might be improve treatment in RA by manipulation of education program regarding medication, nutritional counseling and physical exercises. Recommendations: Establishment specialized exercises program for patients with RA should be mainly included in treatment course.
\end{abstract}

\section{Keywords: Rehabilitation Guideline, Patient Rheumatoid Arthritis, Foot \& Ankle.}

\section{Introduction}

Rheumatoid arthritis (RA) is an inflammatory disease that exerts its greatest impact on those joints of the body that are lined with synovium, a specialised tissue responsible for maintaining the nutrition and lubrication of the joint. The distribution of joints affected (synovial joints) is characteristic. It typically affects the small joints of the hands and the feet, and usually both sides equally in a symmetrical distribution, though any synovial joint can be affected. In patients with established and aggressive disease, most joints will be affected over time.

(Alan, 2010).

The initial trigger for RA is unknown. There is evidence to suggest abnormalities in components of the immune system that lead to the body developing abnormal immune and inflammatory reactions, particularly in joints. These changes may precede the symptomatic onset of RA by many years. Whatever sets the pathology in motion results in a large increase in blood flow to the joint (giving heat and sometimes redness), proliferation of the synovial membrane with an increase in synovial fluid (swelling), and pain (due to stretching of pain receptors in the soft tissues around, and the bone on either side, of the joint. ( Van der Helm et al., 2007). Rheumatoid arthritis (R.A.) is the common form of inflammatory arthritis, which affects $10 \%$ of total world population. The Arab countries face a significant increase in the incidence of the rheumatoid disease of up to $1.5 \%$ of the population. In the Fifth Scientific Conference of Rheumatology and Rehabilitation 2010, participant doctors reported that, the incidence of (R.A.) is increasing in the age group between 30 to 50 years, about 1\% of Egyptians suffer from rheumatoid arthritis, and more of them are female than male. (Hansson et al., 2010).

Rheumatoid arthritis (RA) is a progressively destructive disease Gradual loss of hand function , in RA patients affects their ability for self- care and interferes with their productivity in society. Wrist involvement in RA is common, with in 2 years of diagnosis, more than half of patients will have wrist pain and more than $90 \%$ will have wrist disease by 10 years. Also wrist involvement is generally thought to be less disability than RA of the fingers and hand; it can be a significant cause of pain and disability.

(Kozlow, 2011).

The foot is often the first area of the body to be systematically affected by rheumatoid arthritis (RA). Upon diagnosis, approximately $16 \%$ of patients with RA have foot involvement and it is estimated that the hands and wrists are affected in $80-90 \%$ of RA patients. In $15 \%$ of cases the forefoot is the first area of the body to become symptomatic, and virtually $100 \%$ of patients report foot problems within 10 years of RA onset. (Walmsley, 2010).

Rheumatoid arthritis usually is treated by the following, analgesics, and non steroidal anti 
inflammatory drugs, Potential side effects of these NSAID medications include the development of stomach and duodenal ulcers, It is important to inform patients of potential side effects so that they can report them early to avoid the risk of gastrointestinal hemorrhage. (Coady, 2007).

Currently, there is no curative therapy for RA; therefore, patients are subjected to various life-long treatment modalities. Thus, an important component of successful management of the disease is educating patients and informing them about the planned treatment modalities. (Navarro \& Millán, 2013).

Therefore, the present study has carried out in an attempt to evaluate the effect of rehabilitation program on patient's knowledge and practice for patients with RA at rheumatology and rehabilitation department and rheumatology outpatient clinic at Assiut University Hospital as indicated by enrich, improvement of patient's knowledge and improving the activity of daily living (ADL) related to RA of hands, foot and ankle, relieve of joint pain and preventing joint stiffness, improvement muscle strength and increase/protect of functional status for this patients.

\section{Significance of the study}

Rheumatoid arthritis (RA) is a chronic autoimmune arthritis that causes significant morbidity and mortality and affects almost $1 \%$ of the global population. Patients with RA have a 7-fold higher risk of disability as compared with age- and gendermatched controls. They gradually lose their functional capacity and at the end of 15 years nearly $30 \%-50 \%$ of the patients are in functional class III/IV and need help for vocational/self-care activities. Along with functional disability, RA has an impact on the emotional and psychological functioning of the patient. (Gabriel \& Sokka et al., 2003).

A major goal of rehabilitation guideline focus on help patient with RA to understand and manage the daily tasks essential to be able to lead an active life and enabled to participate in work, social, and self - care activities, and help each patient maximize his or her functional independence. So, data generated from this study could help in Assessing and managing care for patients with rheumatoid arthritis; It is also hoped that findings will generate attention and motivation for further investigations into this topic as well as the lack of local researches that concern with such a problem necessitate the condition of this study.

Content \& validity was done by (5) experts in medical surgical nursing field and medical staff. Their opinions were elicited regarding the consistency and scoring. The content tools was tested regarding to knowledge accurancy, revelance, competence, understanding, applicability and easiness for administrative minor modification were required.

\section{Aim of the study}

The present study was conducted in the rheumatology and rehabilitation department and rheumatology outpatient clinic at Assiut University Hospital to assess patient's knowledge and practices in relation to disease and degree of self- care activities before the implementation of rehabilitation guideline Research hypotheses To fulfill the aim of the study, the following hypotheses are formulated: The post mean knowledge and practice scores of patients who will received the rehabilitation guidelines will higher than their pre- mean knowledge and practice scores.

\section{Research hypothesis}

To fulfill the aim of the study, the following hypotheses are formulated:

1- the post mean knowledge and practice scores of patients who will receive the rehabilitation guidelines will higher than pre- mean knowledge and practice scores.

2- the patients who will receive rehabilitation guidelines are more likely to be able to participate in work and self- care activities.

3- A positive relationship will exist between knowledge and practice scores obtained by patients receiving the rehabilitation guidelines.

\section{Subject and methods}

Design: A quasi-experimental design was used in condition of the study.

Study setting: The study was conducted at rheumatology and rehabilitation department and rheumatology outpatient clinic at Assiut University Hospital according to record cards for follow up, regulated to have hospital management as medication every month and exercises accordingly, the collection of data and application of rehabilitation guidelines lasted over a period of twelve months, starting from August, 2012 and ending in 30 July 2013, Data were collected through individually interview between researcher and patients.

Subjects: A convenient sample of patients with rheumatoid arthritis who attended at rheumatology and rehabilitation department and rheumatology outpatient clinic at Assiut University Hospital. The sample was calculated using the Epi-Info statistical package, version 3.3 with power analysis of $80 \%$, a value of $2-5$ is chosen as the acceptable limit of precision (D) at $95 \%$ level of confidence (CI), with expected prevalence $10 \%$, and worst acceptable $25 \%$, Accordingly, sample size was estimated to be 50 patients with rheumatoid arthritis $+10 \%$ to guard against non-respondense rate, So the total sample was 
60 patients with rheumatoid arthritis , A purposive sample of fifty female patients with rheumatoid arthritis was recruited, were included equitably divided in two equal groups, 25 patients for each group. Group 1; patients with hand and wrist RA. And group 2, patients with foot and ankle RA. The inclusion criteria were: Age is 18:60 years, Duration of disease from three to five years and the degree of RA is moderate \& severs. Free from RA of arms and shoulders, severe cardiac disease (heart failure, recent myocardial infarction), pulmonary disease, inflammatory or muscle disease or previous hand or arm injuries and lower extremity injury or operation.

Tools of the study: Health assessment patient's needs questionnaire sheet (HAQ) Tool (1): This tool originally developed for assessment of personal activity of patients suffering from rheumatoid arthritis (RA), it was developed by Fries. et al., (1980), at stand ford University. this tool consists of three parts; Part(1): Socio-demographic data for patient:- This part included patient's name, age, telephone number, level of education, occupation, disease duration, living situation, occupation status, weight and height ( body mass index(BMI)). Part (2): Assessment of patient's knowledge and practice regarding rheumatoid arthritis: This part was concerned with patient's knowledge regarding to RA topics (definition, causes, risk factors, complications, methods of diagnosis, treatments and its precautions) by using brazil patient knowledge questionnaire (BKQ), Bird et al., (1991) it is an instrument for measuring the knowledge of patient with rheumatoid arthritis( RA) as regards their disease, it contains a multiple choice 16 questions with choice of 80 possible answers, one point for each correct answer ; maximum possible score is 30 ; this questionnaire was used prior to an implementation of the rehabilitation sessions to assess the exact knowledge level, the same was used immediately (immediate post test) and after 2 months later to evaluate the gain in knowledge after implementation of the rehabilitation sessions. Scoring system: one point for each correct answer, and used t-test in statistical analysis and get gain ratio among pre/post 1 and pre/post 2 .

Part(3):Assessment the effect of rheumatoid arthritis on ability of patient to function in activity daily living (ADL); this part used prior to an implementation of rehabilitation program to assess the effects of rheumatoid arthritis( RA) on ability of patient to function in activity of daily living (ADL), assess eight categories (dressing, arising, eating, walking, hygiene, reach, grip, and common activity daily living). And 18 items indicate the amount of pain in joint of hand and wrist; feet and ankle . the same tool was used immediately (post test 1) and after two month later (post test 2) to evaluate the gain practice after implementation of rehabilitation program. The patient assessment will guide the selection and use of these interventions to optimize an individual plan of care and maximize the patient's opportunity to prevent disability and maintain function. Scoring system: Each point is scored on a 5 point likert scale from 4 (unable to do ) to 0 ( no difficult at all), and related to amount of pain each point scored from 0 (for non pain) to 4 ( sever pain).

Tool (2): The foot and ankle disability (FADI) This questionnaire designed by Noyes et al, 1989, for assessing activity levels and limitations in lower extremity including, pain intensity, swelling, overall activity level, walking, stairs, running activity and jumping or twisting; The assessment should focus on ascertaining how an individual patient spends the day, what are the patient's routine or common activities, and what difficulties does the patient encounter in performing the activities; contain 20 items measure routine and daily activity and 4 items indicate the amount of pain in feet and ankle scored. Scoring system: Each of the 20 items is scored on a 5- point likert scale from 0 (unable to do) to 4 (no difficult at all) and the 4 pain items are scored 4

(none) to 0 (unbearable).

Tool(3): Michigan hand outcome Questionnaire (MHQ) This questionnaire designed by Pillsbury MS et al. (1998) was developed to measure health state domains important to patient with hands disorders, include 37 multiple choice questions, divided in to:(1) overall hand function (17 items). (2) work performance and hands/wrists problem interference and amount of pain (10 items). (3) patient satisfaction with hand function (10 items). These tools were used before application of rehabilitation sessions as this (pre/immediately post $1 /$ post 2 ). \& suggested measure for hand grip strength: These tool suggested through implementation the rehabilitation program ensure and strongly evaluate the results of implementation program, were used grip strength test GST-2013®, portable electronic scale (f.g.1) specification $40 \mathrm{~kg} / 20 \mathrm{~g}$, was modified by made metal hanger, stainless steel frame $12 \times 25 \mathrm{~cm}$ length , metallic hanger and two metallic bar upper bar and lower bar and cover this two bare by two pieces of sponge covered by a piece of cloth folding and covering the bar portable electronic scale standby mode at zero, patients were encouraged to catching the two bar by her fist and press hard as they could and repeat this three times and the researcher registered three reading.

\section{Methods}

Techniques for data collection: an official permission to carry out the study at related setting was obtained by the researcher from the head of the rheumatology and rehabilitation department. ethical 
consideration: before the initial interview, an oral consent was secured from each patient after being informed about the nature, purpose and benefits of the study. Patients were also informed that participation is voluntary and about their right to withdraw at any time without giving reasons; the investigator emphasized that the participation is voluntary and confidentiality and anonymity of the patients will be assured through coding all of data. confidentiality of any obtained information was ensuring through coding of all data. The researchers reassured patients that the data would be used for only the research purpose.

Content validity :The content validity was done by expertise in the medical surgical nursing field and rheumatology field, and a Pilot study was conducted during August, 2012. It included 10 patients, A pilot study selected from the same study settings in order to test the clarity and applicability of the tools. According the required modifications was done. and then the final forms were developed and the subjects were not excluded from the actual study.

\section{Description of the rehabilitation program}

Preparatory phase: in which the researcher designed and tested the proposed teaching protocol after extensive literature review (nursing textbooks, Journals, internet resources, etc) about rheumatoid arthritis causes, complications, treatment and rehabilitation guidelines include. Education (knowledge) exercises for hand and wrist; foot and ankle exercises. Treatment and instruction about medication for RA and practice in daily activity for patients with RA, then the final form of the proposed rehabilitation guidelines was checked to facilitate the implementation of the teaching rehabilitation guidelines about Rheumatoid arthritis (Pictures, videotapes and handouts). This was followed by arranging for the teaching rehabilitation guidelines schedule based on the contents of program., number of patients time availability.

\section{Plan of session}

At initial session: Identification the patient and make orientation about guidelines. Interview the patient with Rheumatoid arthritis (female patients) individually to assess their knowledge and their condition and how the disease affected on their daily activity. The initial interview the researcher introduce herself to initiate line of communication, explain the purpose of the program and fill out the (HAQ) health assessment questionnaire sheet (tool 1) Also she scheduled with them the teaching sessions for both theory and practice and the patients were divided into small groups each group contains 7 patients each group of patients was given. The freedom to choose their optimal day (according to her day which receive monthly medication) and other patient in patient word according time available for them afternoon or morning or night) for receiving the rehabilitation guidelines. The rehabilitation guidelines has been implemented in 4 session's in addition to preliminary session, these 4 sessions were repeated each group, the duration of each session ranged from 30-45 minutes, including 15 minutes for discussion and feedback, each session usually started by a summary of what has been taught in the previous session and objectives. from 30-45 minutes, including 15 minutes for discussion and feedback.

Evaluation post program: It was done after two months from the last session, but through two months the researcher follow up the patients with (RA), through met them individually (two to three times per month) at outpatient clinic or in patient ward to ensure that they performed exercises at home.

\section{Statistical analysis}

Optioned data were subjected to; $\mathrm{T}$ - test for comparison of means; a probability level of 0.05 was adopted as level of significance for testing the research hypothesis, Z-test for proportion; 1.96 was adopted as level of significance; Correlation coefficient and high confidence limit ( HCL) and low confidence limit (LCL) by mean of Advanced statistical Analysis package (ASAP).( Darwish 2013). 


\section{Results}

Table (1): Socio-demographic characteristics both groups. $(n=50)$.

\begin{tabular}{|c|c|c|}
\hline Age (years) & Frequency & Percent \\
\hline$<40$ & 19 & $38 \%$ \\
\hline 40 to less than 50 & 24 & $48 \%$ \\
\hline $50 \&$ more & 7 & $14 \%$ \\
\hline Mean \pm SD & \multicolumn{2}{|c|}{$40 \pm 9.34$} \\
\hline \multicolumn{3}{|l|}{ Duration disease/Year. } \\
\hline Mean \pm SD & $4.3 \pm 0.76$ & \\
\hline morning stiff/ hrs Mean \pm SD & $0.84 \pm 0.24$ & \\
\hline \multicolumn{3}{|l|}{ RF } \\
\hline negative & 6 & 12 \\
\hline positive & 44 & 88 \\
\hline \multicolumn{3}{|l|}{ Level of education } \\
\hline University level & 1 & 2 \\
\hline Moderate level & 9 & 18 \\
\hline Read and write & 13 & 29 \\
\hline illiterate & 27 & 54 \\
\hline
\end{tabular}

Table (2): frequency distributing in relation to scores/values that indicate the foot and ankle function status. (group 1).

\begin{tabular}{|l|c|c|c|c|c|c|c|}
\hline \multicolumn{1}{|c|}{ Items } & Before & After1 & z value & Sig. & After 2 & z value & Sig. \\
\hline 1-Standing & 0.65 & 0.66 & 0.20 & $\mathrm{~ns}$ & 0.60 & 1.20 & $\mathrm{~ns}$ \\
\hline 2- Walking on even ground & 0.58 & 0.60 & 0.50 & $\mathrm{~ns}$ & 0.60 & 0.50 & $\mathrm{~ns}$ \\
\hline 3- Walking on even ground without shoes & 0.68 & 0.71 & 0.80 & $\mathrm{~ns}$ & 0.74 & 1.60 & $\mathrm{~ns}$ \\
\hline 4- Walking up hills & 0.68 & 0.86 & 4.50 & $* *$ & 0.72 & 1.00 & $* *$ \\
\hline 5- Walking down hills & 0.65 & 0.84 & 4.75 & $* *$ & 0.71 & 1.50 & $* *$ \\
\hline 6-Going up stairs & 0.64 & 0.76 & 3.00 & $* *$ & 0.67 & 0.80 & $* *$ \\
\hline 7- Going down stairs & 0.58 & 0.64 & 1.50 & $\mathrm{~ns}$ & 0.60 & 0.50 & $\mathrm{~ns}$ \\
\hline 8- Walking on uneven ground & 0.61 & 0.69 & 2.00 & $*$ & 0.69 & 1.95 & $\mathrm{~ns}$ \\
\hline 9- Stepping up and down curves & 0.75 & 0.79 & 1.00 & $* *$ & 0.76 & 0.25 & $* *$ \\
\hline 10- Squatting & 0.48 & 0.49 & 0.25 & $\mathrm{~ns}$ & 0.48 & 0.00 & $\mathrm{~ns}$ \\
\hline 11- Sleeping & 0.58 & 0.74 & 4.00 & $* *$ & 0.62 & 0.90 & $* *$ \\
\hline 12- Coming up to your toes & 0.56 & 0.58 & 0.50 & $* *$ & 0.55 & 0.25 & $* *$ \\
\hline 13- Walking initially & 0.57 & 0.62 & 1.35 & $\mathrm{~ns}$ & 0.63 & 1.55 & $\mathrm{~ns}$ \\
\hline 14- Walking 5 minutes or less & 0.56 & 0.63 & 1.75 & $\mathrm{~ns}$ & 0.60 & 1.00 & $\mathrm{~ns}$ \\
\hline 15- Walking 15 minutes or greater & 0.60 & 0.68 & 2.00 & $\mathrm{~ns}$ & 0.65 & 1.25 & $\mathrm{~ns}$ \\
\hline 16- Home responsibilities & 0.60 & 0.71 & 2.75 & $* *$ & 0.68 & 2.00 & $* *$ \\
\hline 17- Activities of daily living & 0.60 & 0.78 & 4.50 & $* *$ & 0.71 & 2.75 & $* *$ \\
\hline 18- Personal care & 0.52 & 0.62 & 2.50 & $*$ & 0.56 & 1.00 & $\mathrm{~ns}$ \\
\hline 19- - ight to moderate work (standing, walking) & 0.66 & 0.72 & 1.50 & $\mathrm{~ns}$ & 0.71 & 1.25 & $\mathrm{~ns}$ \\
\hline 20- Heavy work (push/pulling, climbing, carrying) & 0.73 & 0.82 & 2.35 & $\mathrm{~ns}$ & 0.83 & 2.55 & $\mathrm{~ns}$ \\
\hline 21- General level of pain & 0.60 & 0.80 & 5.00 & $* *$ & 0.76 & 4.00 & $*$ \\
\hline 22- Pain at rest & 0.48 & 0.56 & 2.00 & $*$ & 0.55 & 1.75 & $\mathrm{~ns}$ \\
\hline 23- Pain during normal activity & 0.60 & 0.80 & 5.00 & $* *$ & 0.76 & 4.00 & $* *$ \\
\hline 24- Pain first thing in the morning & 0.60 & 0.94 & 8.50 & $* *$ & 0.78 & 4.50 & $* *$ \\
\hline
\end{tabular}

Statistically significant at $Z>1.96$ ns $Z \leq 1.96^{*} \quad Z \leq 2.58^{* *}$ 
Table (3) : Related To Overall Hand Functions Of Study Patients With Hand And Wrist RA.

\begin{tabular}{|l|c|c|c|c|c|c|c|c|}
\hline \multicolumn{2}{|c}{ Items } & Before & After1 & z value & Sig. & After 2 & z value & Sig. \\
\hline hand work & 1 & 0.7 & 0.58 & 3.50 & $* *$ & 0.51 & 5.25 & $* *$ \\
\hline fingers move & 2 & 0.5 & 0.44 & 2.00 & $*$ & 0.38 & 3.40 & $* *$ \\
\hline wrist move & 3 & 0.6 & 0.49 & 3.60 & $* *$ & 0.41 & 5.55 & $* *$ \\
\hline strength hand & 4 & 0.7 & 0.66 & 1.00 & $\mathrm{~ns}$ & 0.59 & 2.60 & $* *$ \\
\hline sensation (feeling) in hand & 5 & 0.5 & 0.49 & 1.20 & $\mathrm{~ns}$ & 0.49 & 1.20 & $\mathrm{~ns}$ \\
\hline Turn a door knob. & 6 & 0.8 & 0.67 & 3.20 & $* *$ & 0.67 & 3.20 & $* *$ \\
\hline Pick up a coin. & 7 & 0.7 & 0.66 & 1.60 & $\mathrm{~ns}$ & 0.66 & 1.60 & $\mathrm{~ns}$ \\
\hline Hold a glass of water. & 8 & 0.4 & 0.38 & 1.40 & $\mathrm{~ns}$ & 0.37 & 1.80 & $\mathrm{~ns}$ \\
\hline Turn a key in the lock. & 9 & 0.8 & 0.65 & 5.00 & $* *$ & 0.65 & 5.00 & $* *$ \\
\hline Hold a frying pan. & 10 & 0.8 & 0.65 & 3.00 & $* *$ & 0.62 & 3.80 & $* *$ \\
\hline Open a tight or new Jar. & 11 & 0.9 & 0.7 & 5.00 & $* *$ & 0.69 & 5.40 & $* *$ \\
\hline Button a shirt or blouse. & 12 & 0.8 & 0.6 & 4.00 & $* *$ & 0.6 & 4.00 & $* *$ \\
\hline Eat with a knife and fork. & 13 & 0.6 & 0.58 & 1.20 & $\mathrm{~ns}$ & 0.58 & 1.20 & $\mathrm{~ns}$ \\
\hline Carry a grocery bag. & 14 & 0.8 & 0.68 & 3.40 & $* *$ & 0.68 & 3.40 & $* *$ \\
\hline Wash dishes. & 15 & 0.5 & 0.44 & 2.20 & $*$ & 0.44 & 2.20 & $*$ \\
\hline Wash your hair. & 16 & 0.7 & 0.59 & 3.60 & $* *$ & 0.62 & 3.00 & $* *$ \\
\hline Tie shoelaces or knots & 17 & 0.7 & 0.56 & 3.60 & $* *$ & 0.57 & 3.40 & $* *$ \\
\hline
\end{tabular}

Statistically significant at $Z>1.96$ ns $Z \leq 1.96 * Z \leq 2.58 * *$

Table (4) : Related To Work Performance And Hands/ Wrists Problem Interference And Amount Of Pain.

\begin{tabular}{|l|c|c|c|c|c|c|c|c|}
\hline \multicolumn{1}{|c|}{ Items } & & Before & After1 & $\begin{array}{c}\mathbf{z} \\
\text { value }\end{array}$ & Sig. & $\begin{array}{c}\text { After } \\
\mathbf{2}\end{array}$ & $\begin{array}{c}\mathbf{z} \\
\text { value }\end{array}$ & Sig. \\
\hline $\begin{array}{l}\text { How unable to do work because hand } \\
\text { problems }\end{array}$ & 18 & 0.46 & 0.59 & 3.35 & $* *$ & 0.51 & 1.40 & $\mathrm{~ns}$ \\
\hline Shorten in work day because hand problem & 19 & 0.38 & 0.54 & 4.00 & $* *$ & 0.54 & 4.00 & $* *$ \\
\hline How often did you have to take easy at work. & 20 & 0.52 & 0.65 & 3.25 & $* *$ & 0.61 & 2.20 & $*$ \\
\hline $\begin{array}{l}\text { How often did you accomplish less in work } \\
\text { because hand problem }\end{array}$ & 21 & 0.48 & 0.58 & 2.40 & $*$ & 0.58 & 2.60 & $* *$ \\
\hline How often did you take longer to do tasks in work. & 22 & 0.26 & 0.44 & 4.60 & $* *$ & 0.44 & 4.60 & $* *$ \\
\hline How often did have pain in hands /wrists & 23 & 0.28 & 0.54 & 6.40 & $* *$ & 0.47 & 4.80 & $* *$ \\
\hline describe the pain in hands/ wrists & 24 & 0.72 & 0.52 & 5.00 & $* *$ & 0.56 & 4.00 & $* *$ \\
\hline How often did the pain interfere with sleep & 25 & 0.33 & 0.53 & 5.00 & $* *$ & 0.54 & 5.40 & $* *$ \\
\hline How often did the pain interfere with daily activity & 26 & 0.38 & 0.6 & 5.60 & $* *$ & 0.58 & 5.00 & $* *$ \\
\hline How often did the pain make unhappy & 27 & 0.35 & 0.66 & 7.60 & $* *$ & 0.59 & 6.00 & $* *$ \\
\hline
\end{tabular}

Statistically significant at $Z>1.96$ ns $Z \leq 1.96 * Z \leq 2.58 * *$

Table (5) : Related To Patient Satisfaction With Hand Function.

\begin{tabular}{|c|c|c|c|c|c|c|c|c|}
\hline Items & & Before & After1 & z value & Sig. & After 2 & z value & Sig. \\
\hline I was satisfied with the appearance of my hand & 28 & 0.67 & 0.5 & 4.20 & $* *$ & 0.5 & 4.40 & $* *$ \\
\hline The appearance of my hand sometimes made me un happy & 29 & 0.57 & 0.48 & 2.25 & $*$ & 0.5 & 1.50 & ns \\
\hline The appearance of hand made me depressed & 30 & 0.59 & 0.48 & 2.75 & $* *$ & 0.5 & 2.00 & $* *$ \\
\hline The appearance of hand interfered with normal social activities & 31 & 0.5 & 0.48 & 0.40 & ns & 0.6 & 1.80 & ns \\
\hline Overall function of hand & 32 & 0.48 & 0.62 & 3.40 & $* *$ & 0.6 & 0.58 & ns \\
\hline Motion of the fingers in hand & 33 & 0.5 & 0.64 & 3.50 & $* *$ & 0.6 & 2.00 & $*$ \\
\hline Motion of wrist & 34 & 0.55 & 0.64 & 2.25 & $*$ & 0.5 & 1.00 & ns \\
\hline Strength level of hand & 35 & 0.48 & 0.6 & 3.00 & $* *$ & 0.6 & 3.00 & $* *$ \\
\hline Pain level of hand & 36 & 0.62 & 0.72 & 2.60 & $* *$ & 0.7 & 2.60 & $* *$ \\
\hline Sensation (feeling) your hand & 37 & 0.46 & 0.58 & 3.00 & $* *$ & 0.6 & 3.00 & $* *$ \\
\hline
\end{tabular}

Statistically significant at $Z>1.96$ ns $Z \leq 1.96 * \quad Z \leq 2.58 * *$ 


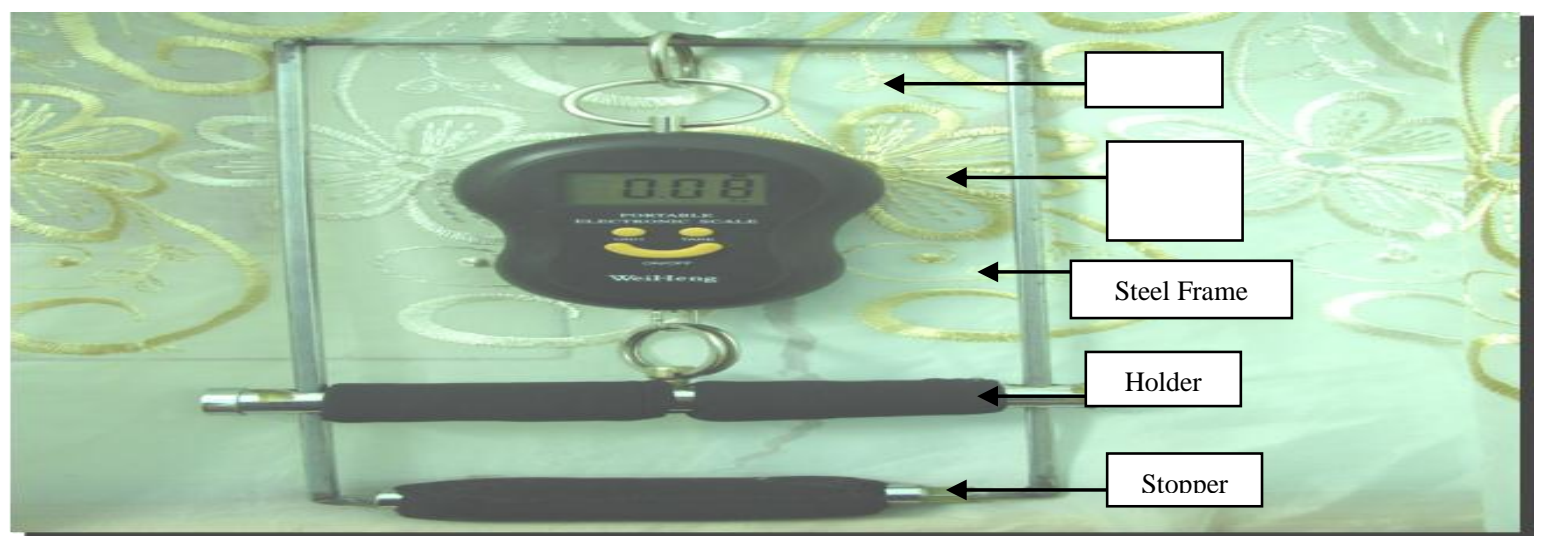

Fig. (1).

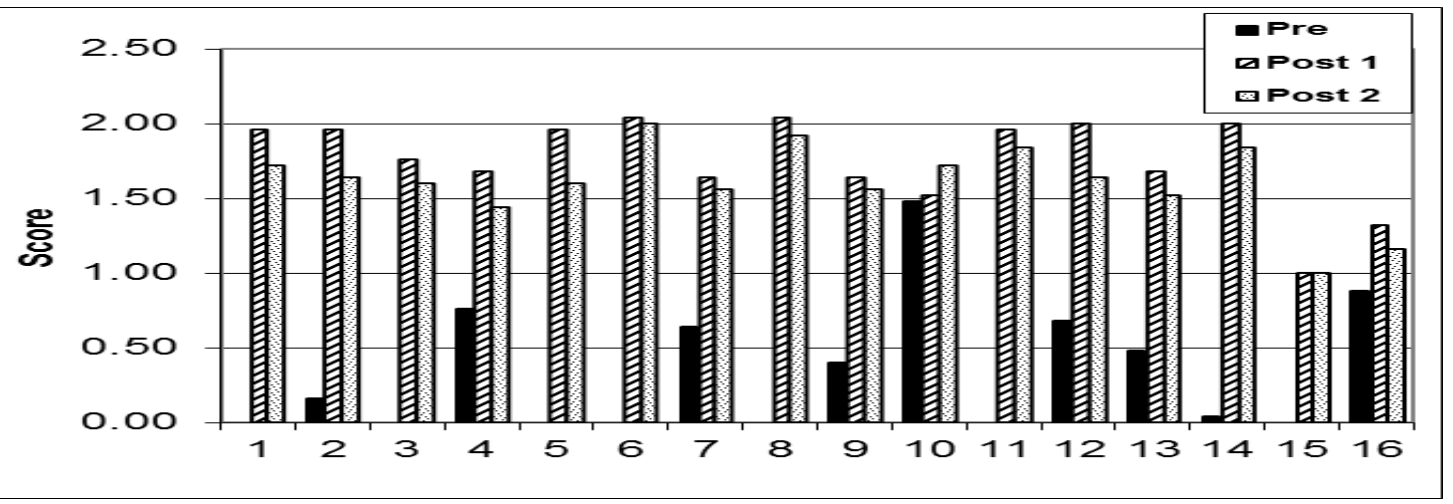

Fig(2) : Assessment patient's knowledge regard RA ,pre, immediately post test (1) and after application of the rehabilitation program and after two month (post 2 ).

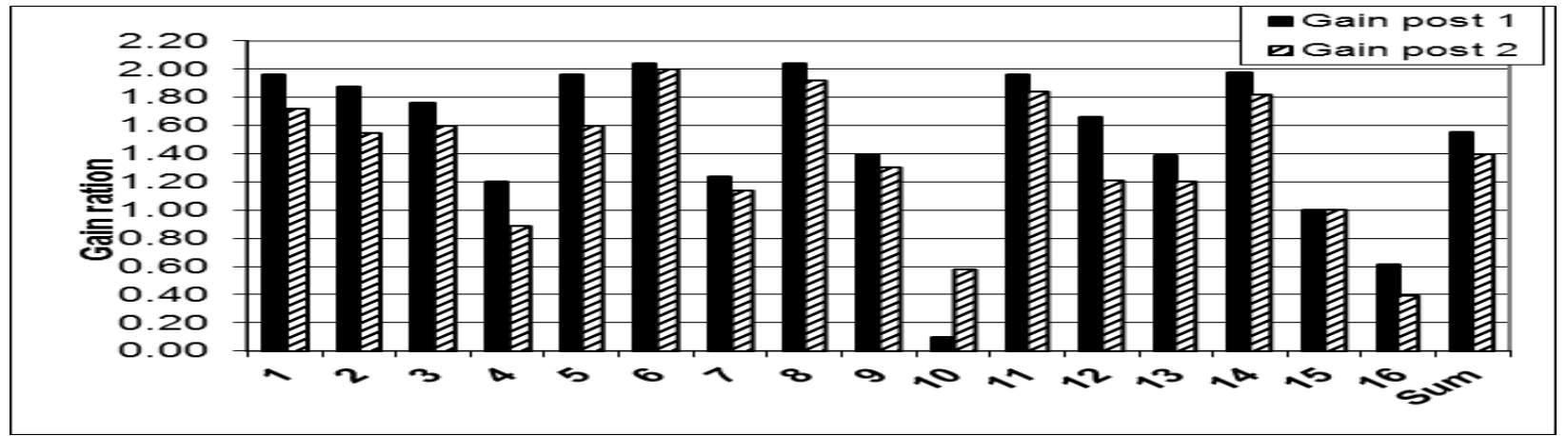

Figure(3) : gain ratio related to knowledge among study patients in post (1) /post (2).

1- Def. of RA

2- Affect of RA

3- Causes of RA

4- Blood test for RA

5- Diet for RA

6- Side effect anti inflammatory

7- Pain medicine

8- Benefit of exercises

$Z>1.96$ ns $Z \leq 1.96 * \quad Z \leq 2.58 * *$
9- Common exercises for RA

10- Practice and stiff joint

11- Dealing with sore and stiff joint

12- Protect joint strain

13- Daily activity

14- Save energy

15- Protect joints

16- High risk for RA. 


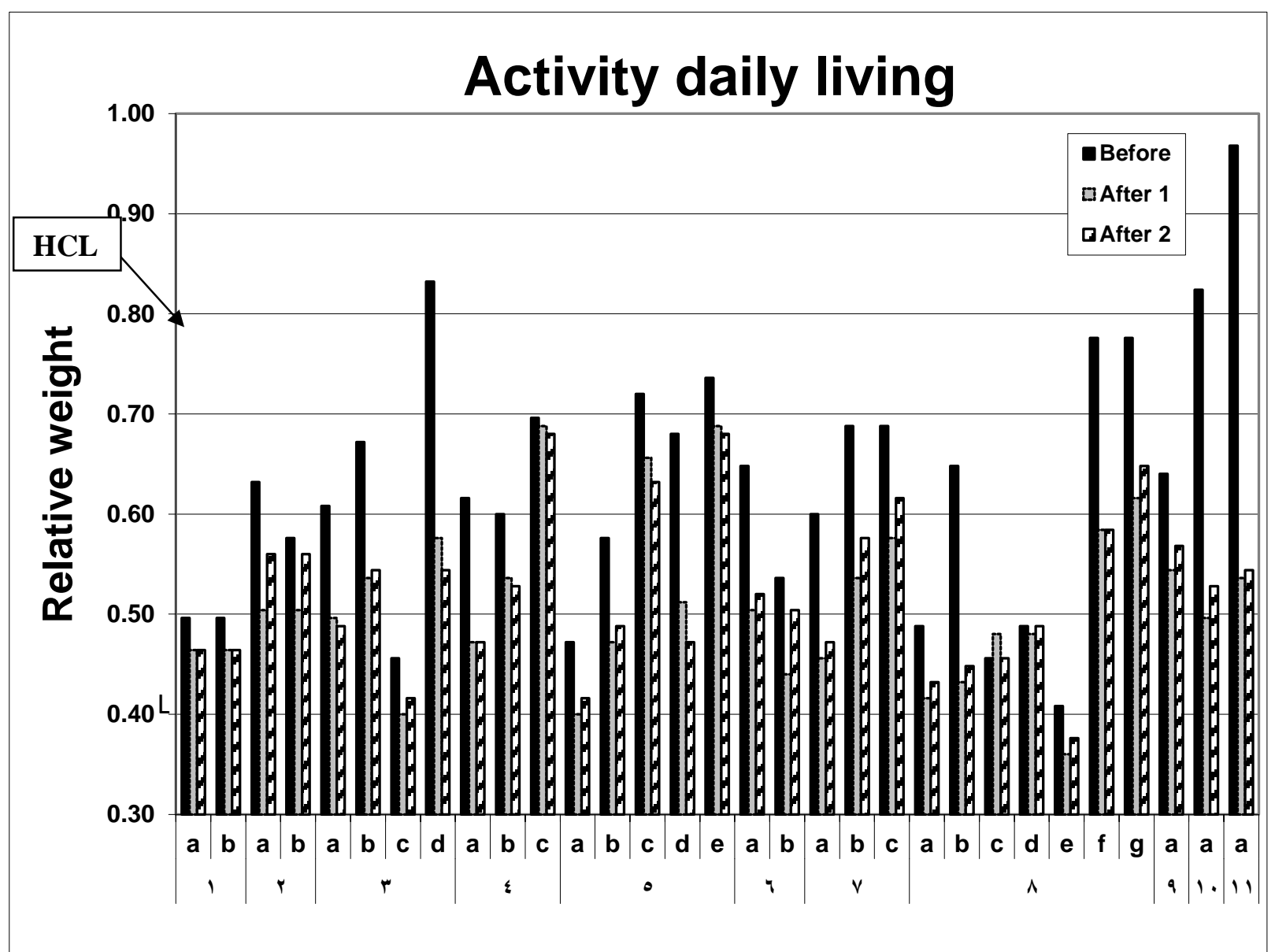

Figure (4): common activity daily living for patients in pre, immediately post test(1) immediately after application of the rehabilitation program and after 2 month (post 2).

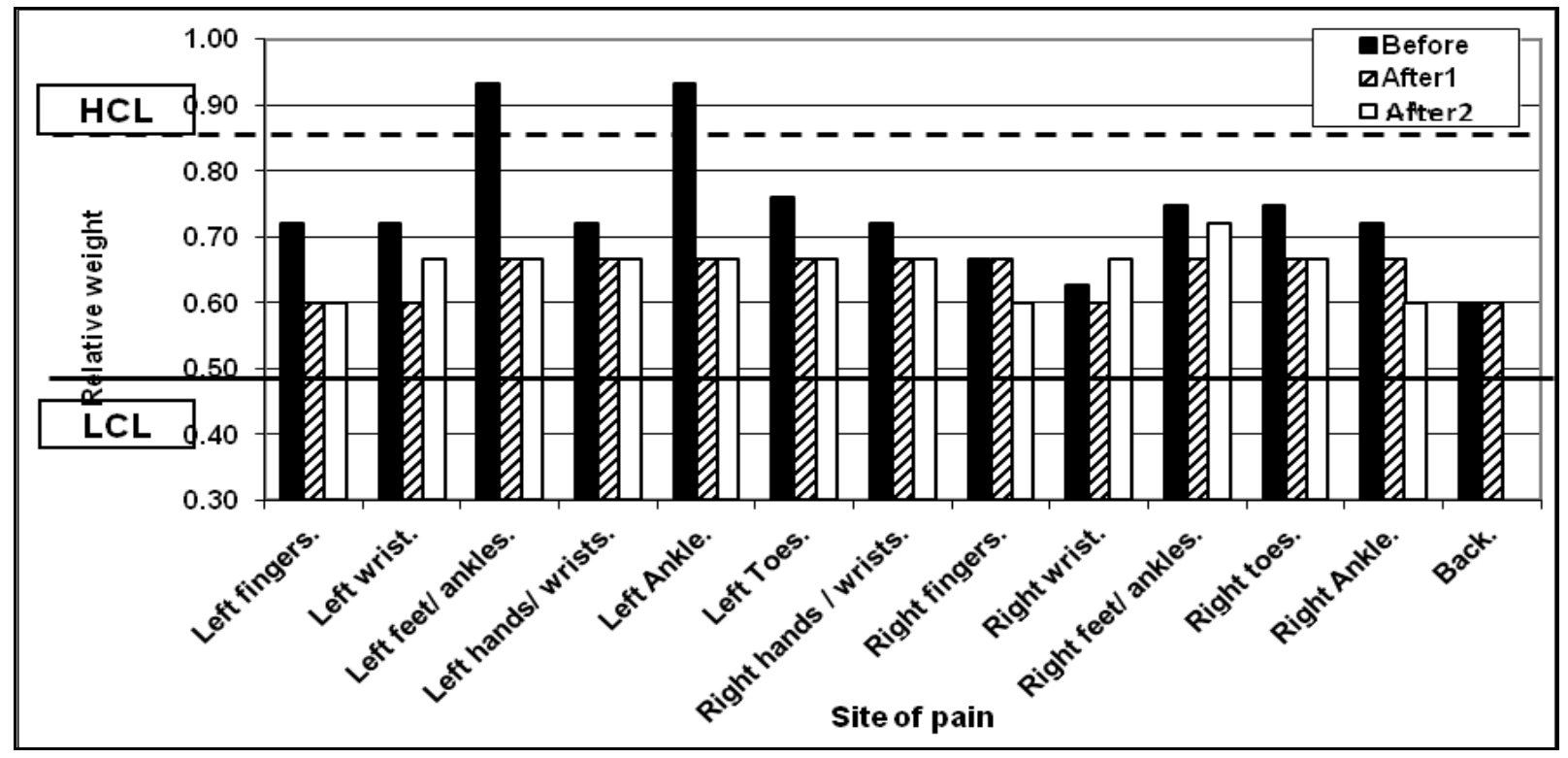

Figure(5): site of pain of patients ( group 1); pre, immediately post test (1) immediately after application of the rehabilitation program and after two month (post 2 ).

$H C L$

0.85

$L C L$

0.49 


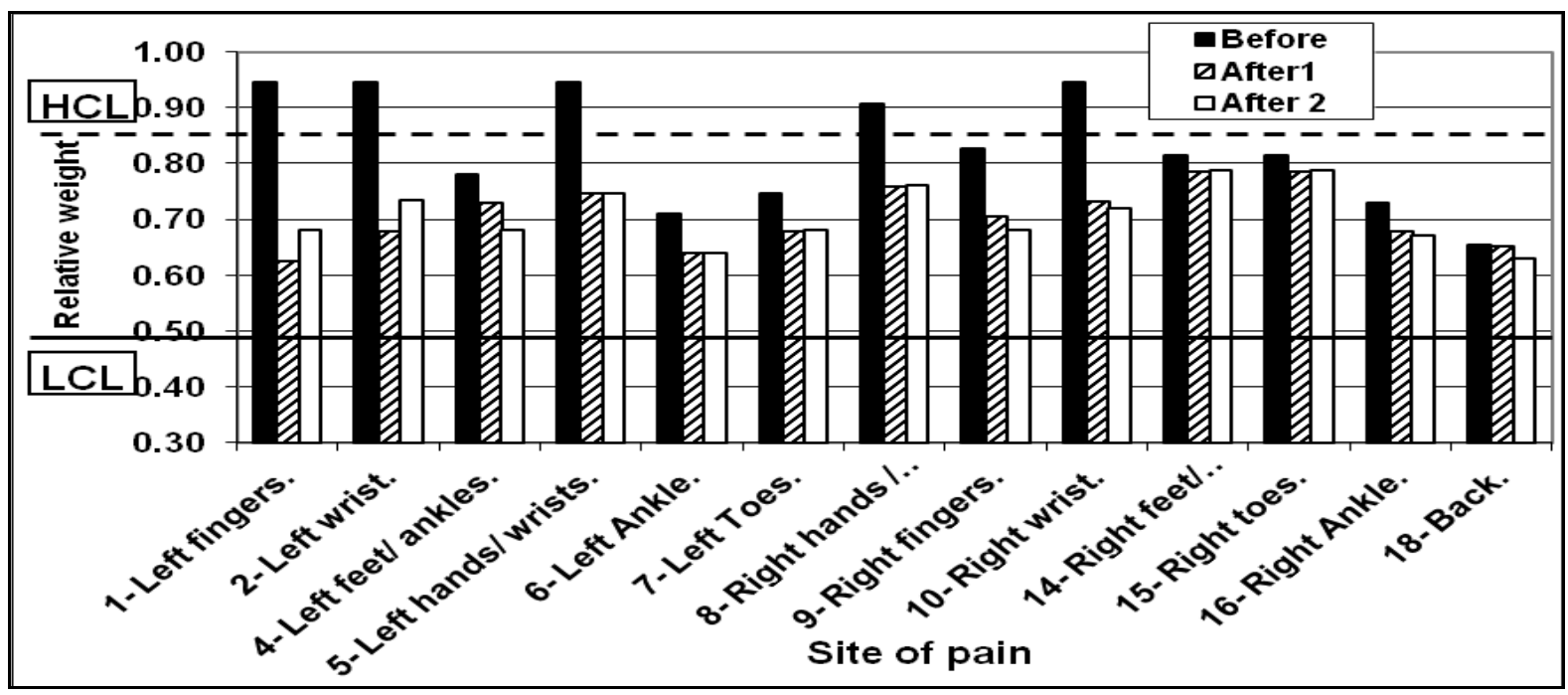

Figure (6): site of pain of patients ( group 2); pre, immediately post test (1) immediately after application of the rehabilitation program and after two month (post 2 ).

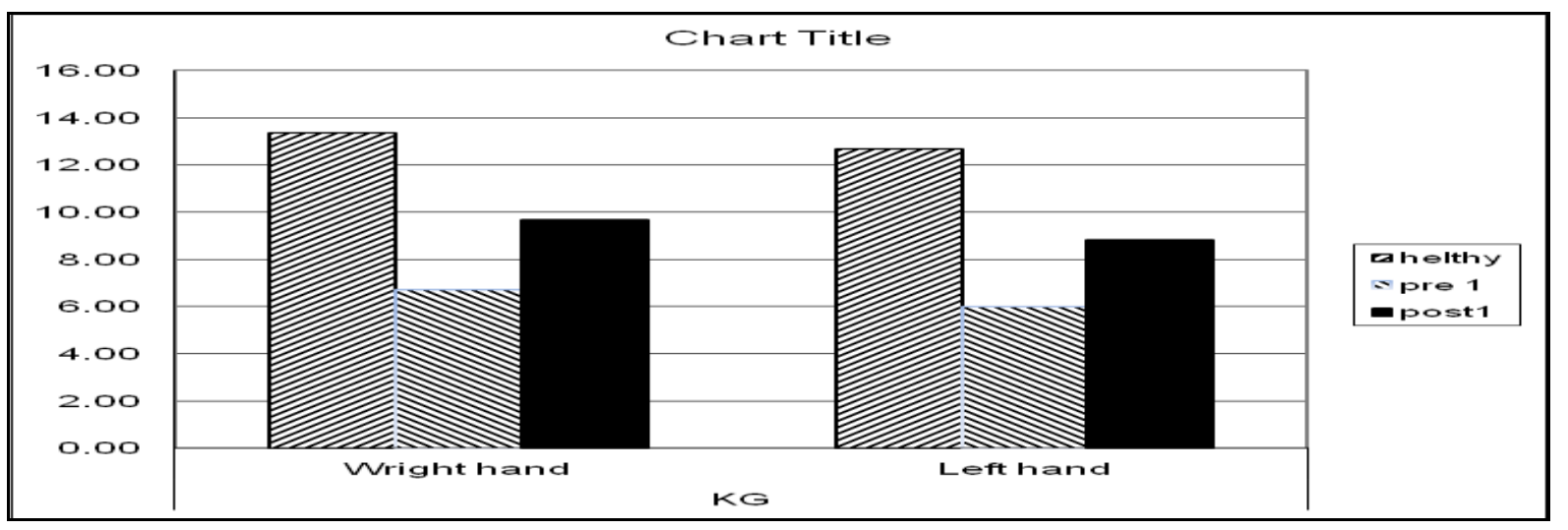

Figure (7): Comparison between healthy person and patients with rheumatoid arthritis after regular exercises program for hand and wrist Through using grip strength test GST-2013 ${ }^{\circ}$, portable electronic scale by KG.

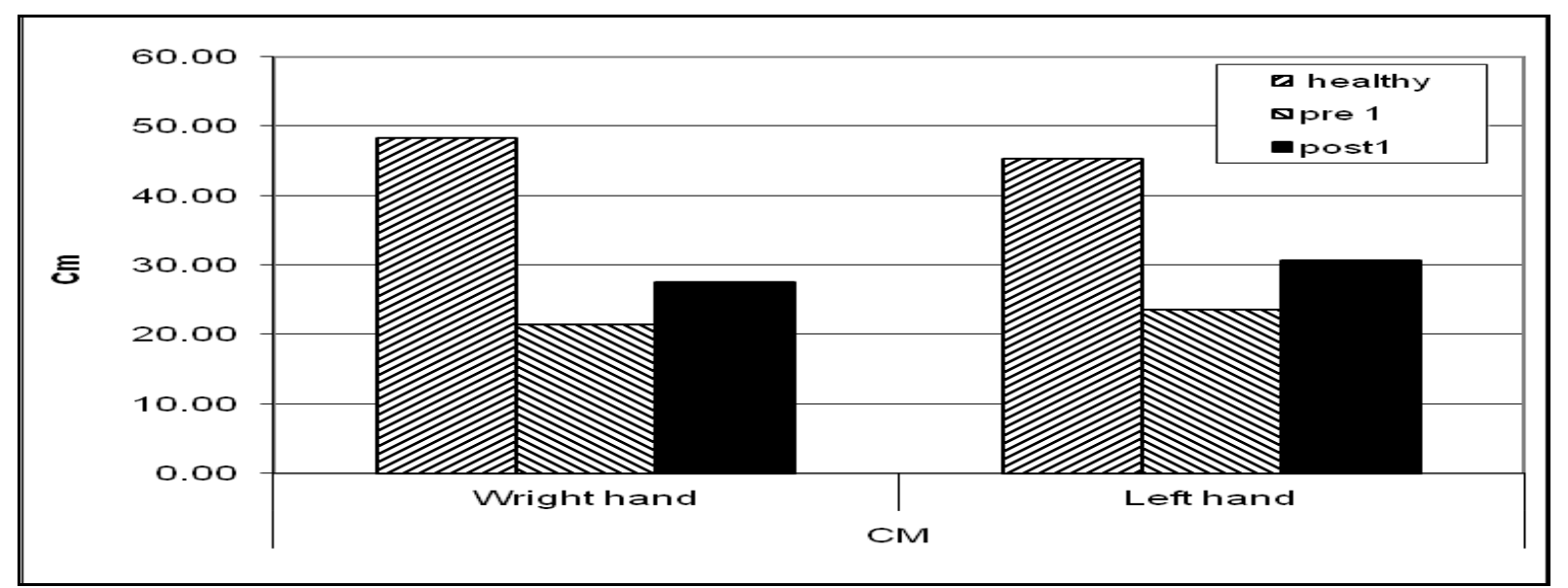

Figure (8): Comparison between healthy person and patients with rheumatoid arthritis after regular exercises program for hand and wrist through using professional aneroid sphygmomanometer. 
The aim of the present study was to evaluate the effect of rehabilitation guideline on patient's knowledge and practice as well as on improving the activity of daily living (ADL) of patients with rheumatoid arthritis of hands, foot and ankle at rheumatology and rehabilitation department and rheumatology outpatient clinic at Assiut university Hospital.

Table (1): show the socio-demographic characteristics of both groups in this study (patients with RA hand and wrist; group 1 and RA foot and ankle group 2) the total study sample was 50 female patients with RA, their mean ages was $40.3 \pm 9.3$ years. The vast majority of them $(54 \%)$ was illiterate and $(88 \%)$ were positive RF, and their mean years of duration of disease was $(4.3 \pm 0.76)$ and morning stiff by mean ( $0.84 \pm 0.24) \mathrm{hrs}$. ranging 0.5 to 1 hour.

Table (2): shows there were statistical significant differences improvement indicates the foot and ankle functional status and routine daily activity among female patients with RA; foot and ankle of study patients show that there were highly statistical significance difference improvement were noticed in pre and follow up of rehabilitation program phases. were noticed in pre and follow up of rehabilitation program phases and highly statistical significant differences related to pain level during normal activity.

Table (3): Reveals that there were highly statistical differences improvement were noticed among study patients related to over all hand function in pre and follow up of rehabilitation program phases also can be seen mean while no statistical differences improvements detected regarding some items.

Table (4): Reveals that there were highly statistical differences improvement were noticed among study sample related patient work performance and hands/wrists problem interference and amount of pain highly significant $(\mathrm{z}=6.4$ in post 1 and 4.8 in post 2$)$.

Table (5): Reveals that there were highly statistical differences improvement were noticed among study sample related patient satisfaction with hand function in pre and follow up of rehabilitation program phases also can be seen changed from highly statistical significant to significant or non-significant.

Figure (1): These tool suggested through implementation the rehabilitation program ensure and strongly evaluate the results of implementation program, were used grip strength test GST-2013®, portable electronic scale specification $40 \mathrm{~kg} / 20 \mathrm{~g}$, was modified to measure grip strength for patients with RA hand and wrist in pre and post exercises program for hands and wrists.

Figure (2) \& figure(3): Show the assessment patient's knowledge regard RA pre, immediately post test (1) and after application of the rehabilitation program and after two month (post 2) there were highly statistical significant difference $(\mathrm{P} \leq 0.01 * *)$; improvements were noticed in pre and post test follow up of rehabilitation program phases among study sample regarding knowledge about RA, and also this table show that there were gain rate related to knowledge among study patients in pre /post (1) more than gain rate in pre/post (2); meaning that the gain rate of knowledge started decrease in follow up after two month from the implementation rehabilitation program. Also we can see there were highly significant difference $(\mathrm{p}<0.001)$ by mean $(7.00 \pm 2.50)$ in pre test increased to $(23.9 \pm 4.6)$ in post 1 , and still there were highly significant difference in post 2, by mean (20.96) which illustrated that patients with RA need continuous education program as a part of routine treatment .

function health status among study sample related to common activity daily living showed in figure(4). there were highly statistical significant difference throughout rehabilitation program phases among study sample regarding total scores of common activity daily living, also from figure(4) illustered that daily activity among study sample ranging between the line of (LCL) and (HCL) and skip confidence limit which means worse function health status related to activity daily living; while approximately of items dropped off to below (HCL) which means there were improvements throughout rehabilitation program phases among study samples related to common activity daily living moved from worse function health status into better( moderate) health status.

figure (5): Indicates the site of pain scores obtained by patients; pre, immediately post test (1) immediately after application of the rehabilitation program and after two month (post 2) there were highly statistical significant difference improvements throughout rehabilitation program phases among study patients group (1) related to common amount of pain related to common amount of pain in joint only five items there is no statistical significant difference regarding left hands/wrists, right hands/wrists, right fingers, right wrist and back.

figure (6): Indicates the site of pain scores obtained by patients; pre, immediately post test (1) immediately after application of the rehabilitation program and after two month (post 2) there were highly statistical significant difference improvements throughout rehabilitation program phases among study patients group (2) only five items there is no statistical significant difference regarding left toes, right feet and ankle, right toes, Wright ankle, and back ..

Figure (7): shows that there was statistical significant when compared the hand grip strength of 
RA patients with the general population (healthy person). Also there was highly statistical significant when used sphygmomanometer in measurement showed in figure (8).

\section{Discussion}

Rheumatoid arthritis (RA) is the most common inflammatory polyarthritis; it is a chronic unpredictable disorder that can cause persistent joint pain, joint damage and long-term disability (especially in the hands and feet). (Symmons et al., 2002). Although there is no cure for the disease, the overall goals of management are to prevent or control joint damage, maximize function and decrease pain (American College of Rheumatology 2002). All current UK clinical guidelines for the management of RA recommend the use of physiotherapy (PT) and occupational therapy (OT) as an adjunct to drug treatment (Deighton \& Luqmani et al., 2009) The three most common components of PT/OT for RA hands are exercise therapy, joint protection advice and provision of functional splinting and assistive devices (Hammond, 2004).

Patient education is a multi-stage learning process. The purpose of RA patient education is to improve patients ${ }^{\text {ee }}$ knowledge levels and to influence their health behavior positively. On the basis of this information, patients are supposed to be capable of monitoring the disease and managing with it (Hill 2003 Schrieber \& Colley 2004).

A study exploring the important of education for patients with RA to increase their knowledge level and improve their self managements strategies, that confirmed by the present findings reveal that, there were highly significant statistical difference improvement $(\mathrm{p}<0.001)$ were noticed in pre and post test follow-up of rehabilitation program phases regarding knowledge about RA among both groups, also there were gain rate of knowledge in (pre /post 1) more than gain rate of knowledge in (pre /post 2) which meaning that the gain rate of knowledge started decrease in follow up after two month from implementation of rehabilitation program. Also, There were highly significant statistical difference regarding to total scores of common daily activity in both groups $\left(\mathrm{z} \leq 2.58 .^{* *}\right)$

Regarding to patient's knowledge about RA for two groups of this study shows that related to knowledge for two study groups respectively the patient knowledge (PKQ) illustrated that there were highly statistical significant difference improvement were noticed between pre and post test by mean $(7.00 \pm 2.50)$ to $(23 \pm 4.64),(\mathrm{P}<0.001)$ in post test $(1)$ after one month of application program, these agreement with Mwidimi Ndosi et al., (2011): reported that, patient knowledge $(\mathrm{PKQ}=4.39$, 95\% CI [3.35-5.72], P < 0.001).

Also, the finding of the present study show that, there were still highly statistical significant even in post test (2) after two month of application of rehabilitation program but is not the desired image also the finding of the present study show that there were differences in knowledge gain ratio through of follow up of rehabilitation program phases this explained that the patients with RA need constantly education program related to disease and medication, exercises and psychological status. These finding might be due to the patients with RA need to constantly education support and help in adaptation and teaching them how to cope with disease related to problem of everyday life this findings agree with Riemsma et al., (2002): reported that in their review neither information only nor counseling programmes showed any significant effects as to RA patientse health behavior. Also Taal et al., (1996) suppose that RA patient education should lead not only to changes in knowledge, but also to changes in behaviour (e.g. exercising, coping, problem-solving) and health status (e.g. pain, disability, depression).

(Hill, 2003 Schrieber \& Colley 2004) stated that, Patient education is a multi-stage learning process. The purpose of RA patient education is to improve patients $^{\text {ee }}$ knowledge levels and to influence their health behavior positively. On the basis of this information, patients are supposed to be capable of monitoring the disease and managing with it.

Nowadays, patient education is, as it was in the 1950 s and 1960s, one of the non-pharmacological treatments in RA (Sarkio, 1996 Goldring, 2000). Even though there are new medications, RA patients ${ }^{\text {ee }}$ self-care is important and patients should learn selfcare skills so that they could cope at home with the varying symptoms caused by the disease (Barlow 2002 Riemsma et al., 2003).

The nurses ${ }^{\text {ee }}$ role in RA patient education often means advising and educating their patients concerning their drug management (Tijhuis et al., 2002). Other educational content involves supporting and motivating patients in their self-care, educating them regarding medication, nutritional counseling, physical exercise and joint protection (Juhola et al., 2007).

Rheumatology nurses often succeed not only in increasing RA patients "e knowledge of RA significantly but also in improving the patientse psychological status by teaching them how to manage their symptoms (Hill et al., 1994).

In the U.S.A. nurse practitioners ${ }^{\text {ee }}$ curriculum includes, for example, domains such as teaching and coaching. This means assessing the patient"s educational needs, creating an effective learning environment, designing a personalized plan for 
learning, providing health education, coaching the patient towards behavioural changes, and evaluating the outcomes of patient education (American Academy of Nurse Practitioners, 2003).

Also these results agree with Mäkeläinen (2009), who stated that, The purpose of rheumatoid arthritis patient education is to increase the patients' knowledge levels, and to improve their selfmanagement strategies, Patient education is a multistage learning process to improve patients ${ }^{\text {ee }}$ knowledge levels and to influence their health behavior positively. In the 1950s, it was important to support patientse physical functioning by encouraging them to self-care (e.g. to make their beds)

Also, the finding of the present study show that, regarding level of education ( 64\%) of the patients included in the study were illiterate degree of education, Almost all the study sample were house wives, these finding agree with Hassan, (1996) who reported that, the majority of the sample ( $87 \%$ )were house wives. These means that the most of wives have the responsibility to do house activities of daily living there for it would be investigated that women would be frustrated if they could not perform these activities. according to lambert ( 1985) concluded that the inability to carry out daily tasks with ease almost certainly contributes to or deficit in psychological well-being. Also Carmona et al., (2001): reported that Most of the RA cases detected in the study were housewives or retired people.

So, this group of patients need knowledge and education program in simple ways and explain by using pictures supported by video to effective change in their knowledge and behavior about dealing with their disease and adaptive with it.

Regarding to common daily activity for two study groups: in the present study findings that in the patients included in the study obtained higher score in pre test by mean ( 0.71 ) which mean worse status for them through daily activity living, this decreased in (post1) to $(0.57)$ by highly statistical significant difference $\left(Z=3.8,\left(Z \leq 2.58^{* *}\right)\right.$ also in (post 2) still there were statistical significant but to a lesser extent ( $0.55, Z=3.2$ ) which means that mobility, physical activity and pain are affected by the disease than dexterity and activities of daily living as regard social domain (social role and social activity) they obtained ( 0.88 ) in daily activities related to make abed, carry a shopping bag or brief case and mange transportation needs (getting from one place to another), also in get a good night's sleep and deal with feelings of depression, these pointes improvement in post 1 and 2 , these agree with(Jump et al., 2004, Treharne et al., 2007, Coady et al., 2007) pointed out that the Painful joints and stress can lead to sleeping problems. Night pain, for example, is a significant problem that causes worry and stress for patients . These findings agree with Hassan, (1996) who stated that the majority of the study sample ( $71 \%$ ) obtained higher scores (5-8) which means worse functional health status, while approximately quarter $(24 \%)$ of the sample obtained score number (4) which means moderate functional health status, only five patients obtained low score (2-3) which indicates better health status, in line with these findings results in show that regarding to common daily activity in pre rehabilitation program approximately of items ranging between ( $\mathrm{LCL}$ ) and (HCL) in addition some items go beyond (HCL), while after rehabilitation program follow up approximately of items dropped off to below ( HCL) which means there were improvements related common daily living among patients participated in rehabilitation program

Also, regarding to participate in recreational activities there were worse status ( 0.82) in pre test these findings disagree with Hassan, (1996) said that, the majority of patients $(61 \%)$ in social role and $(54 \%)$ in social activity obtained low scores (zero- 3) which means that social domain not affected by the disease. On the other hand related to deal with feeling of depression(0.88) in pre test in the present findings this agree with Hassan, H (1996) who reported that, the majority of patients $(68 \%)$ obtained higher score (7-10) in depression this explained that psychological state's of patients was depression wang et al., (2004) also Laajalahti \& Sintonen

(2005). stated that, RA lead to many limitations for patients: social life, hobbies, everyday tasks, personal and social relationships, and physical contact, According to the study by Vaajoki et al., RA patients $^{\text {ee }}$ pain causes them emotional discomfort (Vaajoki et al., 2004). Arthritis pain is reported to be related to a decrease in a person's satisfaction on his or her health status (Minnock et al., 2003), and restricted joint mobility and increased perception of pain have been reported to be the most determining factors in predicting concurrent disability (Holm et al., 1998). on others, leading to feelings of helplessness and lack of control or independence (Taal et al., 1993, Whalley et al., 1997, Melanson \& Downe-Wamboldt 2003, Vaajoki et al., 2004). This influences patientse mood and self-esteem. Female patients have more difficulties in this respect than male patients, because they have the responsibility for housework and childcare (Hwang et al., 2004)

Yvonne et al., (2011): stated that in the inflammatory markers decreased and swelling subsided, the patient continued to have pain. In addition, fatigue, inability to sleep, feeling sad and discouraged because pain limited the activities of patients could do .

Regarding to site of pain, in the present study illustrated that pain assessment for (study group1) a 
significant statistical difference improvement throughout rehabilitation program phases related to common amount of pain in joint ( mean 0.72) in pre test and (0.67) in post $1,(\mathrm{Z}=2.00 *)(\mathrm{Z}>1.96 \mathrm{~ns}, \mathrm{Z} \leq$ $\left.1.96^{*}, Z \leq 2.58^{* *}\right)$, but in the same table there was no statistical significant right and left hand these due to (criteria of group 1 of this study foot and ankle RA), in the present study almost of the patients participate in it reported that pain and morning stiffness better after exercises and soaking hands and ankle in warm water before go to bed at night and early morning, this in line with the findings founded by Bruce \& Becker (2014): stated that Soaking in warm water is one of the oldest forms of medicine, and research has shown warm water therapy works wonders for all kinds of musculoskeletal complaints, including fibromyalgia, arthritis and low back pain. "The research shows our ancestors got it right. It makes feel better, It makes the joints looser. It reduces pain and it seems to have a somewhat prolonged effect that goes beyond the period of immersion.

Also These findings show that improvement in intensity of pain from moderate and sever in pretest to moderate and mild in post 1 , and in post 2 the amount of pain start increase again, these findings, might be due to will drop for the patients in post 2 (after two month of application of rehabilitation program) which meaning and ensure that exercises program and pain management must be within treatment strategies for RA patients and stress follow up and ensure the patients did it as a key part of treatment.

Also in the group 2 in these study related to (common daily activity living ) show that, there were a significant statistical difference was observed between pre and post 1 , but in a higher significance ( $\mathrm{Z}=4.40$ ) highly significant possible that due to criteria of these group (hand and wrist RA) because the common daily activity for women especially housewives depended on hands (dressing, grooming, eating, grip, hygiene...etc) and related amount of pain there were highly statistical significant difference improvement throughout phases of rehabilitation program and there were change in the amount and intensity of pain from sever to mild and moderate .

Physical therapy is used to reduce patientsee arthritis pain and maintain their functioning (Working group established by the Finnish Society for Rheumatology in 2003). In the 1950s, too, it was important to support patients ${ }^{\text {ee }}$ physical functioning by encouraging them to self-care (e.g. to make their beds). In addition, healthy nutrition, mobilizing and rest were important parts of RA patients ${ }^{\text {ee }}$ treatment (Sarkio 1996).

According to David Zelman, (2012). Being in pain can be the most difficult part of living with rheumatoid arthritis. While medicines help, they don't always make the pain go away completely. In fact, most people with rheumatoid arthritis are faced with frequent or ongoing pain that affects their outlook on life and can lead to depression and anger, Onset of RA implies lifelong process of adaptation in all domains of life and through rehabilitation program it can be improved. The patients require long-term centered care and education to help them to increase knowledge, self management strategies, Maureen \& Alison (2014): reported that Exercise is known to have benefits for people with arthritis. However, many people with arthritis do not exercise, often because of joint or muscle pain, weakness, fatigue, or joint swelling. This can lead to loss of joint motion, stiffness, and muscle weakness and tightness. These problems can worsen fatigue and can cause joints to become unstable. However, exercise can decrease pain and can enhance quality of life. Exercise is most beneficial if it is done on a regular basis. Most people can find a way to exercise without increasing their symptoms.

Regarding to RF, the finding of the present study show that majority of the sample included in these study $(88 \%)$ were positive RF this result agrees with Venables, (2013): who reported that Rheumatoid factor (RF): is an antibody that is present eventually in the blood of most people with rheumatoid arthritis. Not all people with rheumatoid arthritis test positive for rheumatoid factor, and some people test positive for rheumatoid factor, yet never develop the disease.

Also, David Zelman, (2012) who reported that, The rheumatoid factor test is a commonly ordered test to help diagnose rheumatoid arthritis. This test measures rheumatoid factor, which is an antibody in the blood that's present in many people with RA. In fact, the rheumatoid factor blood test is eventually positive in $70 \%$ to $80 \%$ of people with RA, although in early arthritis the percentage may be much smaller and Carol Eustice, (2013) reported that about $80 \%$ of adults who have rheumatoid arthritis are positive for rheumatoid factor approximately $20 \%$ of rheumatoid arthritis patients are negative for rheumatoid factor. Also this findings of the present study revealed that, there were highly significant statistical difference improvement related to foot and ankle functional status and routine daily activity $(\mathrm{z} \leq 2.58 * *)$.

Regarding to work performance and hands/wrists problem interference $\&$ amount of pain, in the present study findings that there were highly statistical significant improvement from (mean 0.36 in pretest which mean that sever pain in hand and wrists during work performance) to ( 0.54 in post 1 , which mean improvement related amount of pain to mild), $Z=5$ it is highly statistical significant improvement $\left(Z \leq 2.58^{* *}\right)$. And in post 2 there were 
highly statistical significant improvement related amount of pain, these findings disagree with the finding in the same study in section (2) show that, the finding of the present study show that, there were still highly statistical significant even in post test (2) after two month of application of rehabilitation program but is not the desired image by (mean 20.96 44.92 ); these finding might be due to the knowledge easy to forget for these group of patients but exercises especially after done and touching its usefulness in easing the pain most of the patients mentioned that feeling better and alleviate pain in hands and wrist after continued on the exercises.

The third section related to hand grip strength and correlation for hand grip strength \& body weight index: in the present study findings that, compared the hand grip strength of RA patients with the general population (healthy person) the mean $(6.70 \pm 3.66)$ Wright hand for patients while mean (13.34 \pm 3.44$)$ for healthy patients $(t=12.45)$ highly significant, also left hand by mean ( $5.99 \pm 3.35$ ) for RA patients while mean $(12.67 \pm 3.08)$ for healthy persons, still highly significant $(\mathrm{t}=13.17)$. Also there was highly statistical significant when used sphygmomanometer in measurement, mean (21.49 \pm 12.02 ) of wright hand for RA patients while healthy person mean $(48.32 \pm 11.52)$ by $(\mathrm{T}=27.65)$, and left hand mean (23.56 \pm 13.02$)$ for RA patients and mean (45.39 \pm 12.26$), T=21.71$, for healthy person, these agreement with Brorsson et al., (2009): who stated that; exercise has become an important part of the rehabilitation of patients with rheumatoid arthritis (RA) during recent years, and the benefits of both aerobics and hand-strengthening exercises have been reported this wide variation in hand exercise may be due to the few objective studies regarding the effect of hand exercise on the rheumatoid hand. Studies have shown that daily hand exercise is effective in increasing grip strength Sofia, et al., (2009). reported that the extension and flexion force improved in both groups after 6 weeks $(\mathrm{p}<0.01)$. Hand function $(\mathrm{GAT})$ also improved in both groups $(\mathrm{p}<0.01)$. a significant improvement in hand force and hand function in patients with rheumatoid arthritis was seen after 6 weeks of hand training; the improvement was even more pronounced after 12 weeks. Hand exercise is thus an effective intervention for RA patients, leading to better strength and function.

Related to correlations coefficient between hand grip strength test (HGST) and BWI: there were negative correlation between body mass index (BMI) and grip strength (GST) of hands in both measurement instruments (portable electronic scale (KG) and professional Aneroid sphygmomanometer (CM); however these correlation were not significant (n.s) except in case of sphygmomanometer the left hand which was significant at $0.05(0.40)$ this may be in view of the right hand is used more than the left hand in daily activity work and carry bags and things or in view of coincidence, because always the strength measuring by $(\mathrm{KG})$ not ( $\mathrm{CM})$. this findings disagree with Lee SJ (2008) and Pakjmed (2013) said that study results showed that there is no significant correlation between age with grip and pinch strength $(\mathrm{p}>0.05)$ but BMI considered as an effective parameter on grip and pinch strength for dominant and non dominant hand in moderate and heavy activities $(\mathrm{p}<0.05)$ and correlation test showed that grip and pinch strength for the dominance hand was significantly higher than non-dominant hand for all workloads $(\mathrm{p}<0.05)$.

Helliwell, (1988): reported that a new system for measuring strength of the hand using a torsion dynamometer linked to a microprocessor is described. The system permits analysis of timed squeezes of both grip and pinch and is adjustable to all sizes of hand and degrees of hand deformity. Results obtained with the system were found to be reproducible, and the rigid device was acceptable to a group of patients with arthritic hands. In rheumatoid arthritis there is a marked reduction in maximum grip and pinch strength, together with a prolongation of the time taken to reach this maximum, and increased fatigue.

Strength of this study is that the exercise program will be individually tailored to each patient, reflecting clinical practice, and is designed to ensure a sufficient dose of exercise is delivered. an exercise programmed designed to meet individual needs and physical abilities significantly improves function in RA patients and improve activity daily living. The potential long-term beneficial effects of such interventions at reducing deformity in these patients merit further exploration.

\section{Conclusions}

These finding might be due to the patients with RA need to constantly education support and help in adaptation and teaching them how to cope with disease related to problem of everyday life, Patient education is a multi-stage learning process to improve patients ${ }^{\text {ee }}$ knowledge levels and to influence their health behavior positively and to improve their self-management strategies, knowledge and education program in simple ways and explain by using pictures supported by video most useful to effective change in the knowledge and behavior of RA patients about dealing with their disease and adaptive with it and Marked improvements in pain during daily normal activity, home responsibilities, pain at morning, and general level of pain in intensity from sever to mild and moderate and improvement sleeping ensure that within treatment 
strategies for RA patients.

\section{Recommendations}

The study recommended that

- A continuous an educational and rehabilitation program planned and offered on regular basis to patients in the rheumatology and rehabilitation unit.

- Written simple booklet about RA and its management (included exercises for hands, wrist, foot and ankle demonstrated by pictures) should be provided and available for patients.

- Available education nurse at outpatients clinic of rheumatology and rehabilitation department after attended to intensive course about RA and it is management, exercises program and how to apply with patients, medications and diet education for patients with RA.

- Establishment of continuous rehabilitation program in outpatient clinics to provide health teaching using booklet and illustrated pamphlets for each patient especially those who can't read and write as a high percentage in the present study were illiterates.

- Up raise health awareness of females about the impact of healthy life styles and exercises programmed in the prevention of complication of the RA and living with the disease; this could be in a form of simplified education, and self-package in order to explain lines of treatment and daily selfmanagement and hands, wrist, foot and ankle exercises.

- Assessment of nurses' knowledge and practices in relation to bundle of care of patients with RA.

\section{References}

1. Alan J., Silman, M., FRCP, (2010) : Arthritis Research U., (2010): Arthritis Research UK, Copeman House, Chesterfield S41 7TD, UK publication January 22,.

2. American College of Rheumatology Subcommittee on Rheumatoid Arthritis Guidelines. (2002): Guidelines for the management of rheumatoid arthritis: Arthritis Rheum. Feb;46(2):328-46.

3. Coady D., Armitage C., \& Wright D., (2007): Rheumatoid Arthritis Patientse Experiences of Night Pain. Journal of Clinical Rheumatology 13, $66-69$.

4. Deighton C., O'Mahony R., Tosh J., Turner C., Rudolf M., Group G., ( 2009): Management of rheumatoid arthritis: summary of NICE guidance., 338:b702.

5. Gabriel S., Crowson C., Kremers H., Doran M., Turesson C., O'Fallon W., et al., (2003) :
Survival in rheumatoid arthritis: A populationbased analysis of trends over 40 years. Arthritis Rheum 48:54-8.the National medical Journalof India. Volum 19,Number 4. original Articles 187.

6. Habibi E., Kazemi M., Dehghan H., Mahaki B., Hassanzadeh A., (2013): Hand grip and pinch strength: Effects of workload, hand dominance, age, and Body Mass Index. Pak J Med Sci;29(1)Suppl:363-367 .

7. Hammond A., (2004): Rehabilitation in rheumatoid arthritis: a critical review. Musculoskeletal Care, 2(3):135-151 .

8. Hansson, E., Lundgren, M., Ronnheden, A., Sörensson، E., Bjärnung, Å., and Dahlberg, A., (2010): Effect of an education programme for patients with osteoarthritis in primary care - a randomized controlled trial. BMC، Musculoskeletal Disorders 11:244 Available from: (http://www.biomedcentral.com/14712474/11/244.

9. Hill J., (2003): An overview of education for patients with rheumatic diseases. Nursing Times 99(19), $\quad 26 \quad-\quad 27$ .http://www.nice.org.uk/nicemedia/pdf/CG79.

10. Hwang E., Kim Y., \& Jun SS.(2004): Lived experience of Korean women suffering from rheumatoid arthritis: a phenomenological approach. International Journal of Nursing Studies 41, 239 - 246.Journal List > J Korean Acad Rehabil Med > v.32(2); Apr 2008.

11. Juhola H., Kukkurainen M., \& Suominen T., (2007): Rheumatology nurses ${ }^{e e}$ work-related empowerment Musculoskeletal Care 5, 91 - 97.

12. Kozlow J1., Chung K., (2011): Current concepts in the surgical management of rheumatoid and osteoarthritic hands and wrists. Hand Clin. Feb;27(1):31-41 .

13. Mäkeläinen, P., (2009): Rheumatoid Arthritis Patient Education and Self-Efficacy. Kuopio; University Publications E. Social Sciences 167, $89 \mathrm{p}$.

14. Maureen R., Gecht-sliver, M., OTR, L., \& Alison M., Duncombe, P., OCS, Faaompt (2014) : Patient information: Arthritis and exercise ( Beyond Basics). University of Maryland medical center.

15. Mwidimi Ndosi A., Karen Vinall A., Claire Hale A., Howard Bird C., Jackie Hill A., (2011): The effectiveness of nurse-led care in people with rheumatoid arthritis: A systematic review International Journal of Nursing Studies NS-1795; No. of Pages 13.

16. Saayed A., (2012): Treating of rheumatoid arthritis. The Egyptian Gazette. http://213.158.162.45/ egyptian/index.php Rheumatoid arthritis, Journal of American 
Science

$2012 ; 8(9)$

http://www.jofamericanscience.org

17. Sofia Brorsson, (2009): Asix week hand exercises programme improves strength and hand functions in patients with rheumatoid arthritis. Journal Compilation (C) 2009 Foundation of Rehabilitation Information. ISSN 1650-1977

18. Smeltzer S., Bare B., Hinkle I., \& Cheever K.,(2008): Brunner and Suddarth"s Text book of medical surgical nursing, 11th edition, Lippincoot Williams and Wilkins,P.P.41.

19. Symmons D., Turner G., Webb R., Asten P., Barrett E., Lunt M., Scott D., Silman A., (2002): The prevalence of rheumatoid arthritis in the United Kingdom: new estimates for a new century. Rheumatology (Oxford). Jul;41(7):793800.

20. Treharne G., Lyons A., Hale E., Douglas K., Goodchild C., Booth D., \& Kitas G., ( 2007): Sleep disruption frequency in rheumatoid arthritis: Perceived stress predicts poor outcome over one year. Musculoskeletal Care 5(1), 51 64.

21. Van der Helm-van Mil A., Le Cessie S., Van Dongen H., et al., (2007): A prediction rule for disease outcome in patients with recent-onset undifferentiated arthritis: how to guide individual treatment decisions. Arthritis \& Rheumatism;56(2):433-440.

22. Walmsley S., Williams A., Ravey M., Graham A., (2010): The rheumatoid foot: a systematic literature review of patient-reported outcome measures. J Foot Ankle Res. Jul 9;3:12 